Article

\title{
Probabilistic Linguistic VIKOR Method to Evaluate Green Supply Chain Initiatives
}

\author{
Xiaolu Zhang ${ }^{1, *}$ and Xiaoming Xing ${ }^{2}$ \\ 1 The Collaborative Innovation Center, Jiangxi University of Finance and Economics, Nanchang 330013, China \\ 2 Institute of Industrial Economics, Jiangxi University of Finance and Economics, Nanchang 330013, China; \\ xiaomingxing0@163.com \\ * Correspondence: xiaoluzhang@jxufe.edu.cn; Tel.: +86-0791-8381-3846
}

Received: 17 June 2017; Accepted: 10 July 2017; Published: 13 July 2017

\begin{abstract}
To achieve the goals of sustainable economic and environmental protection, more and more firms intend to implement green supply chain (GSC) initiatives in their products. The adoption of GSC initiatives in turn influences the firms' operations performance. Thus, the firms have to evaluate their performances carefully when implementing GSC initiatives. The performance evaluation of GSC initiatives is a laborious task, which needs to take into account many factors including the inventory level and assurance of supply purchasing-wise and the technical capability and the innovation capability manufacturing-wise, etc. This paper develops a new probabilistic linguistic VIKOR approach to support such an assessment. To do so, a new comparison method of probabilistic linguistic term sets (PLTSs) is first presented to effectively determine the probabilistic linguistic positive ideal solution and the probabilistic linguistic negative ideal solution. Next, a new defuzzification function of PLTSs is proposed to take into account the main-criteria weights and the sub-criteria weights which are represented by PLTSs. Furthermore, several probabilistic linguistic measures are introduced, such as the probabilistic linguistic group utility measure, the probabilistic linguistic individual regret measure and the probabilistic linguistic compromise measure. Finally, the compromise solution is obtained based on these three measures. The desirable advantages of the developed method are summarized as (1) it allows the evaluators to employ PLTSs to express the imprecise performances of the GSC initiatives with respect to various criteria, which greatly improves the elicitation of linguistic information; (2) it presents a probabilistic linguistic compromise solution, which is a maximum probabilistic linguistic group utility for the majority and a minimum probabilistic linguistic individual regret for the opponent. This proposed technique provides a simple and efficient decision making approach to assist the firms to make an appropriate decision in GSC management.
\end{abstract}

Keywords: green supply chain initiatives; probabilistic linguistic term set; multiple criteria decision making; the VIKOR method

\section{Introduction}

Due to increasing public awareness of the need to protect the environment, and the regulatory pressures coming from governments, firms are progressively promoting business practices to assist them in reducing the negative impacts on the environments [1]. The implementation of green supply chain (GSC) initiatives is a good choice for firms to obtain profit and market share objectives by lowering environmental impacts and improving ecological efficiency. For example, in the new product development, many GSC initiatives including the green design, the green packaging, the use of green raw materials, etc., can be implemented by various firms. The adoption of new GSC initiatives in turn requires changes in firms' operational capabilities and resources that may have an adverse effect on firms' operations performance [2]. Thus, it is necessary for the firms to evaluate their performances 
carefully when implementing the GSC initiatives. However, the performance evaluation of GSC initiatives is a laborious task, which usually needs to take into account many factors including the inventory level and the assurance of supply purchasing-wise and the technical capability and the innovation capability manufacturing-wise, etc. This is a kind of multiple criteria decision making (MCDM) problem.

As one of the most popular MCDM techniques, the VIKOR (VlseKriterijuska Optimizacija I Komoromisno Resenje) method [3] has been widely applied in solving complicated decision making problems with crisp values. However, in the performance evaluation of GSC initiatives, the evaluation values are usually imprecise and vague. For instance, in order to select an appropriate time window for implementing green raw materials, an expert panel including one hundred experts is invited to assess various potential time windows under multiple conflicting criteria by using the linguistic term sets (LTS) $L=\left\{l_{1}:\right.$ definitely poor; $l_{2}:$ very poor; $l_{3}:$ poor; $l_{4}:$ fair $; l_{5}:$ good; $l_{6}:$ very good; $l_{7}:$ absolutely good $\}$. It is assumed that forty-five experts employ " $l_{5}:$ good" to express their opinions relating to the time window $a_{1}$ under the technical capability criterion, fifty use " $l_{4}:$ fair" for $a_{1}$, and the other five experts fail to provide their assessments or their assessments are lost in the decision making processes. It is easily observed that the rating of the $a_{1}$ for this expert panel is especially suitable to be modeled by the probabilistic linguistic term set (PLTS) $\left\{l_{4}(0.5), l_{5}(0.45)\right\}$. The PLTS originally developed by Pang et al. [4] is a useful tool to model the uncertainty with qualitative settings, especially in the performance evaluation of GSC initiatives. To solve the performance evaluation of GSC initiatives with PLTSs, this paper attempts to develop a probabilistic linguistic VIKOR method which not only inherits the feature of the classical VIKOR approach but also absorbs the advantages of PLTSs. In this paper, we make the following contributions:

(1). We develop a new comparison method of PLTSs to effectively determine the probabilistic linguistic positive ideal solution and the probabilistic linguistic negative ideal solution;

(2). We introduce a new defuzzification function of PLTSs to take into account the main-criteria weights and the sub-criteria weights which are represented by PLTSs;

(3). We present the probabilistic linguistic group utility measure, the probabilistic linguistic individual regret measure and the probabilistic linguistic compromise measure;

(4). We provide the compromise solution which is obtained based on these three probabilistic linguistic measures.

The remainder of this paper is organized as follows: Section 2 provides a literature review of GSC and the application of MCDM techniques in GSC, Section 3 recalls briefly the idea of classical VIKOR method and the basic concepts of PLTSs, Section 4 develops a new probabilistic linguistic VIKOR approach, Section 5 provides a case study to illustrate the feasibility and effectiveness of the developed method, and Section 6 presents our conclusions.

\section{Literature Review}

\subsection{Green Supply Chain}

GSC management is a good choice for firms to improve their competitive advantages and profits, which has emerged as an organizational philosophy in recent years [5-9]. According to Sarkis [10], GSC management is the process of purchasing, producing, marketing, and performing various packaging and logistic activities while taking the ecological balance into counting. In his extensive literature review, Srivastava [11] defined GSC management as the process of incorporating environmental concerns into supply chain management including product design, material sourcing and selection, manufacturing process, delivery of the final product to the consumers, and the end-of-life management of the product after its useful life. Shang et al. [12] identified six dimensions of GSC management which are listed as the green manufacturing and packaging, environmental participation, green marketing, green suppliers, green stock, and green eco-design. Moreover, several prominent studies $[13,14]$ 
showed that the use of the green raw materials and greening the production process can lead to environmental material substitution, waste reduction, and decreasing the consumption of hazardous and toxic materials. In order to enhance cost savings, Zhu et al. [15] proved that green logistics and packaging are good initiatives to cut energy consumption and packaging waste in GSC management. By investigating the relationship between the implementation of GSC management and the economic performance and competitiveness of a sample of Asian firms, Rao and Holt [13] confirmed that GSC management can effectively improve competitiveness. Recently, Govindan et al. [16] investigated the selection problem of green suppliers in the food industry. They showed that the food industry is mainly focused on the quality criterion and the environmental criterion, and the suppliers that are more advantageous in these two aspects are favored.

\subsection{Application of MCDM Techniques in Green Supply Chain}

Usually, the evaluation of GSC management or the selection of green suppliers is involved with multiple conflicting criteria, which is a kind of typical MCDM problem. Over the last few decades, many MCDM techniques have been applied effectively to the evaluation of GSC management and the selection of green suppliers in GSC management. For example, Azadi [17] introduced two-stage targetsetting DEA (data envelopment analysis) methods to the GSC management of public transportation service providers. Mathiyazhagan et al. [18] employed an AHP (Analytical Hierarchy Process) technique to investigate the pressures for GSC adoption in the mining and mineral industry context. Govindan et al. [16] applied PROMETHEE (a preference ranking organisation method for enrichment evaluations) to select the green suppliers in the food supply chain. On the other hand, owing to the fact that the crisp values are not adequate or sufficient for the decision makers (DMs) to express their preferences, fuzzy set and/or its extensions are used in GSC management. Many fuzzy MCDM methods [19-22] have been applied in GSC management. For instance, Govindan et al. [23] presented an intuitionistic fuzzy DEMATEL (decision-making trial and evaluation laboratory) technique for developing green practices and performances in process of GSC management. Kusi-Sarpong et al. [24] introduced a joint rough sets and fuzzy TOPSIS (technique for order preference by similarity to ideal solutions) to evaluate the GSC practices in the mining industry. Rostamzadeh et al. [25] also proposed a fuzzy VIKOR technique for assessing GSC practices. Based on linguistic preferences contexts, Shen et al. [26] introduced a fuzzy multiple criteria approach for evaluating green supplier's performance in GSC. Tseng et al. [27] introduced a convergence of interval-valued triangular fuzzy numbers-grey relation analysis technique to enhance performance of the GSC management in a Taiwanese electronic focal firm. Moreover, Zhang et al. [28] developed a hesitant trapezoidal fuzzy QUALIFLEX (qualitative flexible multiple criteria method) method to evaluate GSC initiatives in order to achieve sustainable economic and environmental performance under the contexts of hesitant trapezoidal fuzzy numbers-based comparative linguistic expressions. Wang and Chan [2] developed a hierarchical fuzzy TOPSIS approach to assess improvement areas when implementing GSC initiatives. In addition, a series of hybrid MCDM methods [6,29-34] have recently been developed and applied in green supply chain. On the other hand, Mardani et al. [35] presented a systematic review of MCDM techniques in sustainable and renewable energy systems problems. Mardani et al. [36] provided a review on the application and use of MCDM approaches in regard to energy management problems from 1995 to 2015.

\section{Basic Concepts}

\subsection{The Classical VIKOR Approach}

The classical VIKOR approach is one of the well-known MCDM methods, which focuses on the multi-criteria ranking index based on the particular measure of "closeness" to the ideal solution. Consider a MCDM problem which includes a set of feasible alternatives $\left\{a_{1}, a_{2}, \cdots, a_{m}\right\}$ and a set of the predefined evaluation criteria $\left\{c_{1}, c_{2}, \cdots, c_{n}\right\} . x_{i j}$ represents the criteria values of the alternative 
$a_{i}$ over the criterion $c_{j}$ and $w_{j}$ is used to denote the weight of the criterion $c_{j}$. In the classical VIKOR method, all criteria values $x_{i j}(i=1,2, \cdots, m ; j=1,2, \cdots, n)$ and the weights $w_{j}(j=1,2, \cdots, n)$ are the crisp values. The decision steps of the classical VIKOR method for dealing with this MCDM problem are summarized as below:

Step 1. Determine the positive ideal solution $\left(x_{j}\right)^{+}$

$$
\left(x_{j}\right)^{+}=\max _{i=1}^{m} x_{i j}
$$

and the negative ideal solution $\left(x_{j}\right)^{-}$

$$
\left(x_{j}\right)^{-}=\min _{i=1}^{m} x_{i j}
$$

Step 2. Calculate the value $S_{i}$

$$
S_{i}=\sum_{j=1}^{n} w_{j} \frac{\left(x_{j}\right)^{+}-x_{i j}}{\left(x_{j}\right)^{+}-\left(x_{j}\right)^{-}}
$$

and the value $R_{i}$ :

$$
R_{i}=\max _{j} w_{j} \frac{\left(x_{j}\right)^{+}-x_{i j}}{\left(x_{j}\right)^{+}-\left(x_{j}\right)^{-}}
$$

Step 3. Determine the value $Q_{i}$ :

$$
Q_{i}=\eta \frac{S_{i}-\min _{i} S_{i}}{\max _{i} S_{i}-\min _{i} S_{i}}+(1-\eta) \frac{R_{i}-\min _{i} R_{i}}{\max _{i} R_{i}-\min _{i} R_{i}}
$$

Step 4. Identify the best solution or the set of compromise solutions

Using Equations (3)-(5), three ranking lists of alternatives are obtained according to the decreasing order of the values of $S_{i}, R_{i}$ and $Q_{i}$, respectively. The alternative $a_{\sigma(1)}$ (it is the alternative with the first position in the ranking list derived by $Q_{i}$ ) is the best solution if the following two conditions satisfied:

$C_{1}$. Acceptable advantage: $Q\left(a_{\sigma(2)}\right)-Q\left(a_{\sigma(1)}\right) \geq 1 /(m-1)$;

$C_{2}$. Acceptable stability in decision making: The alternative $a_{\sigma(1)}$ is also the alternative with the first position in the ranking lists derived by $S_{i}$ and/or $R_{i}$.

If the condition $C_{1}$ is not satisfied, then the set of alternatives $\left\{a_{\sigma(1)}, a_{\sigma(2)}, \cdots, a_{\sigma(f)}\right\}$ is the compromise solution in which the maximum value of $f$ is determined by the following equation: $Q\left(a_{\sigma(f)}\right)-Q\left(a_{\sigma(1)}\right)<1 /(m-1)$. On the other hand, if the condition $C_{2}$ is not satisfied, then the set of alternatives $\left\{a_{\sigma(1)}, a_{\sigma(2)}\right\}$ is the set of compromise solutions.

The VIKOR approach is widely used to solve complicated decision making problems with crisp values, such as the selection of a renewable energy project [37], post-earthquake sustainable reconstruction [38], financial performance evaluation [39], and selection of the alternative-fuel modes [40], etc. With the rapid development of human social-economic activities, however, it is more and more difficult for the DMs to employ crisp values to express their preferences [41]. Instead, various fuzzy forms of decision data have been developed to model the imprecise preferences [42-46]. To effectively solve the MCDM problems with various fuzzy environments, many extension forms of the VIKOR approach have recently been developed, such as the interval-valued VIKOR [47], the triangular fuzzy VIKOR [48-50], the trapezoidal fuzzy VIKOR [51], the intuitionistic fuzzy VIKOR [52], the interval-valued intuitionistic fuzzy VIKOR [53], the hesitant fuzzy VIKOR method [54,55] and hesitant fuzzy linguistic VIKOR method [56], etc. Recently, Mardani et al. [57] presented a systematic review of the VIKOR technique in the application areas of sustainability and renewable energy. Although useful, these aforementioned VIKOR-based methods fail to solve the real-world MCDM problems with PLTSs. 


\subsection{Basic Concept of PLTSs}

The mathematical form of PLTS is introduced as follows.

Definition 1 [4]. Given an LTS $L=\left\{l_{i} \mid i=0,1, \cdots, \tau\right\}$, a PLTS based on $L$ can be defined as:

$$
L(p)=\left\{L^{(k)}\left(p^{(k)}\right) \mid L^{(k)} \in L, p^{(k)} \geq 0, k=1,2, \ldots, \# L(p), \sum_{k=1}^{\# L(p)} p^{(k)} \leq 1\right\}
$$

where $L^{(k)}\left(p^{(k)}\right)$ is the linguistic term $L^{(k)}$ associated with the probability $p^{(k)}$, and $\# L(p)$ is the number of all different linguistic terms in $L(p)$.

To facilitate its understanding and application, Zhang [58] provided a new mathematical form for expressing the PLTS.

Definition 2 [58]. Given an LTS $L=\left\{l_{1}, l_{2}, \cdots, l_{\tau}\right\}$, let $\Gamma=\{1,2, \cdots, \tau\}$ be a set of the subscripts of linguistic terms in $L$, and let $\Lambda \subseteq \Gamma$ be a subset of $\Gamma$; then the new mathematical expression form of PLTS is provided as below:

$$
L(p)=\left\{l_{\sigma}\left(p_{\sigma}\right) \mid l_{\sigma} \in L, p_{\sigma} \geq 0, \sigma \in \Lambda, \sum_{\sigma \in \Lambda} p_{\sigma} \leq 1\right\}
$$

It is easily observed that the commonly used expression forms of linguistic information, i.e., the ordinal scales-based linguistic variables [59] and the hesitant fuzzy linguistic term sets (HFLTSs) [60], are the special cases of PLTSs because (1) if $\# \Lambda=1$ and $\sum_{\sigma \in \Lambda} p_{\sigma}=1$ the PLTS is mathematically reduced to an ordinal scales-based linguistic variable [59]; (2) if $\Lambda \subseteq \Gamma$ and $p_{\sigma}=1 / \# \Lambda(\sigma \in \Lambda)$, then the PLTS is mathematically reduced to the HFLTS [60] which is considered to have a possibility distribution across the entire LTSs [61].

In practice, the PLTS $L(p)=\left\{l_{\sigma}\left(p_{\sigma}\right) \mid \sigma \in \Lambda\right\}$ is called a complete PLTS if $\sum_{\sigma \in \Lambda} p_{\sigma}=1$, and the PLTS $L(p)=\left\{l_{\sigma}\left(p_{\sigma}\right) \mid \sigma \in \Lambda\right\}$ is called a partial PLTS if $\sum_{\sigma \in \Lambda} p_{\sigma}<1$ [58]. Consider three different PLTSs based on $L=\left\{l_{i} \mid i=1,2,3,4,5\right\}: L_{1}(p)=\left\{l_{4}(0.4), l_{5}(0.6)\right\}, L_{2}(p)=\left\{l_{1}(0.2), l_{2}(0.6), l_{3}(0.1)\right\}$, $L_{3}(p)=\left\{l_{4}(0.9)\right\}$. It is easy to see that the PLTS $L_{1}(p)$ is a complete PLTS, $L_{2}(p)$ and $L_{3}(p)$ are the partial PLTSs. On the other hand, it is easily observed that $\# \Lambda_{1}=2, \# \Lambda_{2}=3, \# \Lambda_{3}=1$. That is to say, the numbers of linguistic terms in these three PLTSs are different. In practice, these situations in which the numbers of linguistic terms in different PLTSs assessments are different and some PLTSs assessments are not complete PLTSs but are partial PLTSs usually happens in the decision making process. To ensure the rationality of the operational results among PLTSs, Zhang [58] further introduced the corresponding normalization method for normalizing the PLTSs before conducting the operation of PLTSs.

Definition 3 [58]. Given an LTS $L=\left\{l_{1}, l_{2}, \cdots, l_{\tau}\right\}(\tau \geq 2)$, a set of PLTSs based on $L$ is denoted as $\wp=\left\{L_{1}(p), L_{2}(p), \cdots, L_{m}(p)\right\}$, and the element $L_{i}(p) \in \wp$ is denoted by $L_{i}(p)=\left\{l_{\sigma}\left(p_{\sigma}^{i}\right) \mid \sigma \in \Lambda_{i}\right\} ;$ then the normalization process of the set of PLTSs $\wp$ can be divided into the following two steps [58]:

(1) If the PLTS $L_{i}(p)$ is a partial PLTS, i.e., $\sum_{\sigma \in \Lambda_{i}} p_{\sigma}^{i}<1$, then the PLTS $L_{i}(p)$ should be normalized into the complete PLTS $\hat{L}_{i}(p)$ as below:

$$
\hat{L}_{i}(p)=\left\{l_{\sigma}\left(p_{\sigma}^{i}+\bar{p}^{i}\right), l_{\rho}\left(\bar{p}^{i}\right) \mid \sigma \in \Lambda_{i}, \rho \in\left(\Gamma \backslash \Lambda_{i}\right)\right\}
$$

where $\bar{p}^{i}=\left(1-\sum_{\sigma \in \Lambda_{i}} p_{\sigma}^{i}\right) / \tau$.

(2) Let $\Lambda_{\wp}=\Lambda_{1} \cup \Lambda_{2} \cup \ldots \cup \Lambda_{m}$ and $\Lambda^{+}=\Lambda_{i} \cap \Lambda_{\wp}$, if $\Lambda_{i} \subset \Lambda_{\wp}(i=1,2, \cdots, m)$, the set of linguistic terms $L^{+}=\left\{l_{\rho} \mid \rho \in \Lambda^{+}\right\}$should be added in the PLTS $\hat{L}_{i}(p)$ until $\Lambda_{i}=\Lambda_{\wp}$, and the probabilities of all the added linguistic terms are zero. 
To effectively measure the deviations and closeness of different PLTSs assessments, Zhang [58] presented the probabilistic linguistic distance measure which is introduced as follows.

Definition 4 [58]. Given an LTS $L=\left\{l_{1}, l_{2}, \cdots, l_{\tau}\right\}$, two normalized PLTSs based on $L$ are denoted by $L_{1}(p)=\left\{l_{\sigma}\left(p_{\sigma}^{1}\right) \mid \sigma \in \Lambda\right\}$ and $L_{2}(p)=\left\{l_{\sigma}\left(p_{\sigma}^{2}\right) \mid \sigma \in \Lambda\right\}$, then the probabilistic linguistic distance between $L_{1}(p)$ and $L_{2}(p)$ is provided as follows:

$$
d\left(L_{1}(p), L_{2}(p)\right)=\frac{1}{2}\left(\frac{\sum_{\sigma \in \Lambda}\left|p_{\sigma}^{1}-p_{\sigma}^{2}\right|}{2}+\frac{\left|\sum_{\sigma \in \Lambda} \sigma p_{\sigma}^{1}-\sum_{\sigma \in \Lambda} \sigma p_{\sigma}^{2}\right|}{\tau-1}\right)
$$

The PLTS is a useful tool to model the uncertainty in qualitative MCDM. Benefiting from the development of information techniques, the decision made by a large number of DMs or participants has become more frequent in recent years. The decision making problems in which the decision data are represented by PLTSs are more and more common nowadays, which have recently received increasing attention from many researchers and practitioners [62-65]. For example, Zhang et al. [64] developed a consistency-based risk assessment approach to handle the group decision making problem with probabilistic linguistic preference relation. Lin et al. [63] developed a probabilistic uncertain linguistic TOPSIS approach to solve the selection problem of cloud storage services.

\section{Proposed Probabilistic Linguistic VIKOR Approach}

To solve the GSC initiatives evaluation problem in which the evaluation values are expressed in PLTSs, we next develop a probabilistic linguistic VIKOR multi-criteria analysis approach, which is motived by the classical VIKOR method. Firstly, the evaluating framework of the green supply chain initiatives is presented in Section 4.1. According to the idea of the classical VIKOR approach, there are two key issues to be addressed in the developed method, i.e., identifying the probabilistic linguistic ideal solutions which are conducted in Section 4.2 and calculating the closeness of each solution to the ideal one by a series of probabilistic linguistic measures which is implemented in Section 4.3. Finally, the procedures of the developed method are introduced in Section 4.4 .

\subsection{The Evaluating Framework of the Green Supply Chain Initiatives}

In practice, the performance evaluation of GSC initiatives usually requires the firms to take many conflicting criteria into account, such as the inventory level, the suppliers and the materials, etc., which should be considered purchasing-wise; the technical capability, the innovation capability and the others should be considered manufacturing-wise; the inbound and outbound logistics, and the packaging, etc., should be considered logistics-wise; and the saleability, marketability and the others should be considered marketing-wise. The framework of the evaluation problem of the GSC initiatives introduced by the studies [2,28] is shown in Figure 1.

It is easily observed from Figure 1 that this evaluation problem is a hierarchical MCDM problem with a two-layered structure. The first layer includes four main-criteria $\left\{c_{1}, c_{2}, c_{3}, c_{4}\right\}$. The weights of the main-criteria are denoted by $\left\{w\left(c_{1}\right), w\left(c_{2}\right), w\left(c_{3}\right), w\left(c_{4}\right)\right\}$ which are represented by PLTSs in this study. Every main-criterion $c_{j}(j \in\{1,2,3,4\})$ includes $\# c_{j}$ sub-criteria $\left\{c_{j(1)}, c_{j(2)}, \cdots, c_{j\left(\# c_{j}\right)}\right\}$ in the second layer, where $\# c_{j}$ denotes the number of sub-criteria in the main-criterion $c_{j}$. The weights of the sub-criteria $\left\{c_{j(1)}, c_{j(2)}, \cdots, c_{j\left(\# c_{j}\right)}\right\}$ are represented by $\left\{w\left(c_{j(1)}\right), w\left(c_{j(2)}\right), \cdots, w\left(c_{j\left(\# c_{j}\right)}\right)\right\}$ which also take the form of PLTSs. Let $x_{i j(k)}$ be the criterion value of the alternative $a_{i}(i \in\{1,2, \cdots, m\})$ with respect to the sub-criterion $c_{j(k)}\left(k \in\left\{1,2, \cdots, \# c_{j}\right\}\right)$ in the main-criterion $c_{j}(j \in\{1,2, \cdots, n\})$. Then, this evaluation problem is mathematically expressed as a probabilistic linguistic decision matrix $\mathcal{R}$ which is shown in Table 1. 


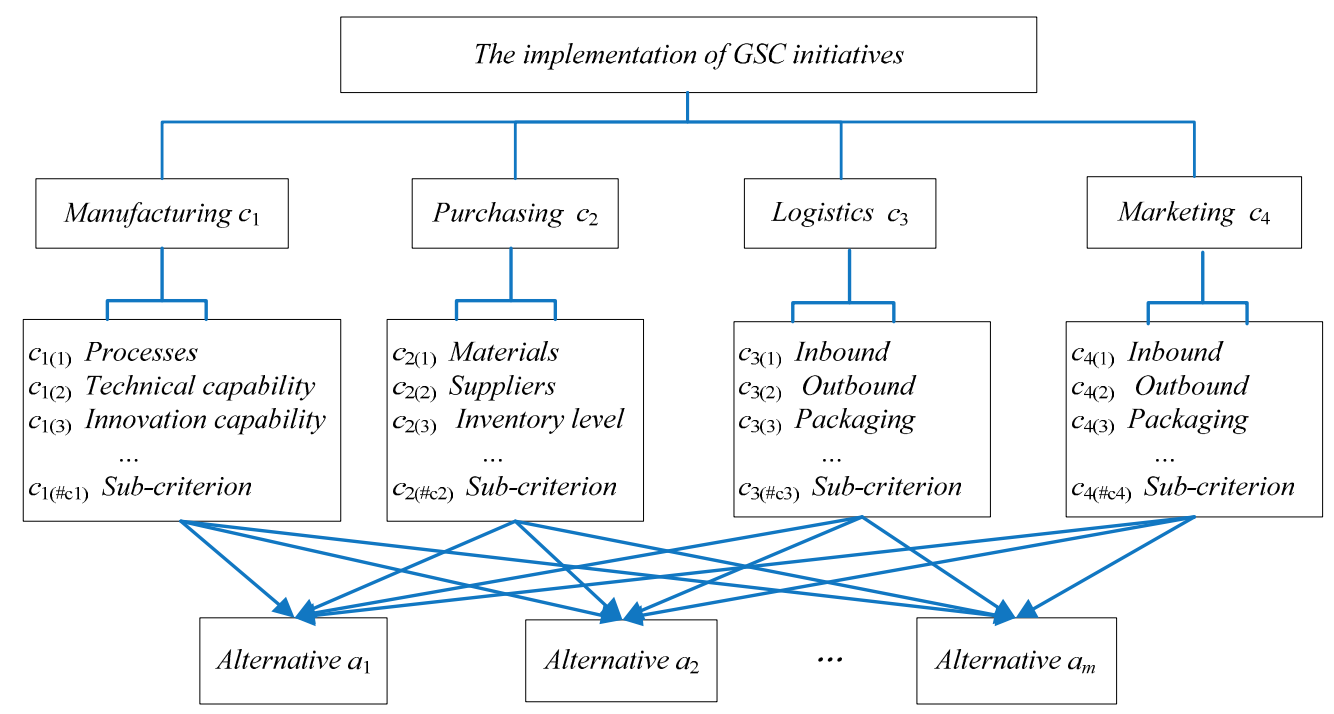

Figure 1. The framework of the performance evaluation of GSC initiatives.

Table 1. The probabilistic linguistic decision matrix.

\begin{tabular}{|c|c|c|c|c|c|c|c|c|c|c|c|c|c|}
\hline \multirow{3}{*}{ Alternatives } & \multicolumn{13}{|c|}{ Evaluation main-criteria and sub-criteria } \\
\hline & \multicolumn{4}{|c|}{$c_{1}$} & \multicolumn{3}{|c|}{$c_{2}$} & \multicolumn{3}{|c|}{$c_{3}$} & \multicolumn{3}{|c|}{$c_{4}$} \\
\hline & $c_{1(\mathbf{1})}$ & $c_{1(2)}$ & $\ldots$ & $c_{1(\# c 1)}$ & $c_{2(1)}$ & $\ldots$ & $c_{2(\# c 2)}$ & $c_{3(\mathbf{1})}$ & $\ldots$ & $c_{3(\# c 3)}$ & $c_{4(\mathbf{1})}$ & $\cdots$ & $c_{4(\# c 4)}$ \\
\hline$a_{1}$ & $x_{11(1)}$ & $x_{11(2)}$ & $\ldots$ & $x_{11(\# c 1)}$ & $x_{12(1)}$ & $\ldots$ & $x_{12(\# c 2)}$ & $x_{13(1)}$ & $\ldots$ & $x_{13(\# c 3)}$ & $x_{14(1)}$ & $\ldots$ & $x_{14(\# c 4)}$ \\
\hline$a_{2}$ & $x_{21(1)}$ & $x_{21(2)}$ & $\ldots$ & $x_{21(\# c 1)}$ & $x_{22(1)}$ & $\ldots$ & $x_{22(\# c 2)}$ & $x_{23(1)}$ & $\ldots$ & $x_{23(\# c 3)}$ & $x_{24(1)}$ & $\ldots$ & $x_{24(\# c 4)}$ \\
\hline$\ldots$ & $\ldots$ & $\ldots$ & $\ldots$ & $\ldots$ & $\ldots$ & $\ldots$ & $\ldots$ & $\ldots$ & $\ldots$ & $\ldots$ & $\ldots$ & $\ldots$ & $\ldots$ \\
\hline$a_{\mathrm{m}}$ & $x_{m 1(1)}$ & $x_{m 1(2)}$ & $\ldots$ & $x_{m 1(\# c 1}$ & $x_{m 2(1)}$ & $\ldots$ & $x_{m 2(\# c 2)}$ & $x_{m 3(1)}$ & $\ldots$ & $x_{m 3(\# c 3)}$ & $x_{m 4(1)}$ & $\ldots$ & $x_{m 4(\# c 4)}$ \\
\hline
\end{tabular}

\subsection{To Determine the Probabilistic Linguistic Ideal Solutions}

To effectively solve the previous decision making problem, we first need to identify the probabilistic linguistic positive ideal solution and the probabilistic linguistic negative ideal solution among all alternatives over each sub-criterion, respectively. To do so, a new comparison method is next developed for comparing the magnitude of PLTSs.

Definition 5. Given an LTS $L=\left\{l_{\sigma} \mid \sigma \in \Gamma\right\}$ and let $\Lambda \subseteq \Gamma$, then a PLTS based on $L$ is denoted as $L(p)=\left\{l_{\sigma}\left(p_{\sigma}\right) \mid \sigma \in \Lambda\right\}$. The expectation value of $L(p)$ is defined as:

$$
\operatorname{Exp}(L(p))=\sum_{\sigma \in \Lambda} \sigma\left(p_{\sigma}+\bar{p}\right)+\sum_{\rho \in(\Gamma \backslash \Lambda)} \rho \bar{p}
$$

where $\bar{p}=\left(1-\sum_{\sigma \in \Lambda} p_{\sigma}\right) / \tau$.

It is easy to see from Definition 5 that if the PLTS $L(p)$ is a complete PLTS, the expectation value of $L(p)$ is reduced to the following form:

$$
\operatorname{Exp}(L(p))=\sum_{\sigma \in \Lambda} \sigma p_{\sigma}
$$

Proposition 1. Let $\operatorname{Exp}(L(p))$ be the expectation value of $L(p)$ derived by Definition 5, the following statements hold:

(1) $1 \leq \operatorname{Exp}(L(p)) \leq \tau ;$ 
(2) $\operatorname{Exp}(L(p))=1$ if and only if $L(p)=\left\{l_{1}(1.0)\right\}$, and theoretically the $\operatorname{Exp}\left(\left\{l_{1}(1.0)\right\}\right)$ is the smallest expectation among all PLTSs based on the LTS L;

(3) $\operatorname{Exp}(L(p))=\tau$ if and only if $L(p)=\left\{l_{\tau}(1.0)\right\}$, and theoretically the $\operatorname{Exp}\left(\left\{l_{\tau}(1.0)\right\}\right)$ is the greatest expectation among all PLTSs based on the LTS L.

\section{Proof.}

(1) According to the definition of PLTSs, it is easy to see that $1 \leq \sigma, \rho \leq \tau$. Thus, we have:

$$
\sum_{\sigma \in \Lambda}\left(p_{\sigma}+\bar{p}\right)+\sum_{\rho \in(\Gamma \backslash \Lambda)} \bar{p} \leq \operatorname{Exp}(L(p)) \leq \sum_{\sigma \in \Lambda} \tau\left(p_{\sigma}+\bar{p}\right)+\sum_{\rho \in(\Gamma \backslash \Lambda)} \tau \bar{p} .
$$
to see:

Let $\mathcal{X}=\sum_{\sigma \in \Lambda}\left(p_{\sigma}+\bar{p}\right)+\sum_{\rho \in(\Gamma \backslash \Lambda)} \bar{p}$ and $\mathcal{H}=\sum_{\sigma \in \Lambda} \tau\left(p_{\sigma}+\bar{p}\right)+\sum_{\rho \in(\Gamma \backslash \Lambda)} \tau \bar{p}$, then it is easy

$$
\mathcal{X}=\sum_{\sigma \in \Gamma}(\bar{p})+\sum_{\sigma \in \Lambda}\left(p_{\sigma}\right), \mathcal{H}=\sum_{\sigma \in \Gamma} \tau(\bar{p})+\sum_{\sigma \in \Lambda} \tau p_{\sigma} .
$$

By $\bar{p}=\left(1-\sum_{\sigma \in \Lambda} p_{\sigma}\right) / \tau$, we obtain:

$$
\begin{gathered}
\mathcal{X}=\sum_{\sigma \in \Gamma}\left(\left(1-\sum_{\sigma \in \Lambda} p_{\sigma}\right) / \tau\right)+\sum_{\sigma \in \Lambda}\left(p_{\sigma}\right)=1-\sum_{\sigma \in \Lambda} p_{\sigma}+\sum_{\sigma \in \Lambda}\left(p_{\sigma}\right)=1, \\
\mathcal{H}=\tau \sum_{\sigma \in \Gamma}\left(\left(1-\sum_{\sigma \in \Lambda} p_{\sigma}\right) / \tau\right)+\sum_{\sigma \in \Lambda} \tau p_{\sigma}=\tau\left(1-\sum_{\sigma \in \Lambda} p_{\sigma}\right)+\sum_{\sigma \in \Lambda} \tau p_{\sigma}=\tau .
\end{gathered}
$$

i.e., $1 \leq \operatorname{Exp}(L(p)) \leq \tau$.

Furthermore, according to (1) in Proposition 1, the proofs of (2) and (3) in Proposition 1 are straightforward.

Definition 6. Given an LTS $L=\left\{l_{\sigma} \mid \sigma \in \Gamma\right\}$ and let $\Lambda \subseteq \Gamma$, then a PLTS based on $L$ is denoted as $L(p)=\left\{l_{\sigma}\left(p_{\sigma}\right) \mid \sigma \in \Lambda\right\}$. The variance value of $L(p)$ is provided as follows:

$$
\operatorname{Var}(L(p))=\sum_{\sigma \in \Lambda}\left((\sigma-\operatorname{Exp}(L(p)))^{2}\left(p_{\sigma}+\bar{p}\right)\right)+\sum_{\rho \in(\Gamma \backslash \Lambda)}\left((\rho-\operatorname{Exp}(L(p)))^{2} \bar{p}\right)
$$

Clearly, if the PLTS L $(p)$ is a complete PLTS, its variance is denoted as follows:

$$
\operatorname{Var}(L(p))=\sum_{\sigma \in \Lambda}\left(p_{\sigma}(\sigma-\operatorname{Exp}(L(p)))^{2}\right)
$$

Meanwhile, for a special PLTS $L *(p)=\left\{l_{1}(0.5), l_{\tau}(0.5)\right\}$, then we have

$$
\begin{gathered}
\operatorname{Exp}(L *(p))=1 \times 0.5+0.5 \times \tau=0.5 \tau+0.5, \\
\operatorname{Var}(L *(p))=0.5(1-(0.5 \tau+0.5))^{2}+0.5(\tau-(0.5 \tau+0.5))^{2}=(0.5 \tau-0.5)^{2}=0.25(\tau-1)^{2} .
\end{gathered}
$$

Theoretically, the $\operatorname{Var}(L *(p))$ is the greatest variance among all PLTSs based on the LTS L.

Based on the expectation values and variance values of PLTSs, the comparison law for PLSTs is introduced as follow.

Definition 7. Given two PLTSs $L_{1}(p)$ and $L_{2}(p)$, let $\operatorname{Exp}\left(L_{1}(p)\right)$ and $\operatorname{Exp}\left(L_{2}(p)\right)$ be the expectation values of $L_{1}(p)$ and $L_{2}(p)$, respectively, $\operatorname{Var}\left(L_{1}(p)\right)$ and $\operatorname{Var}\left(L_{2}(p)\right)$ be the variance values of $L_{1}(p)$ and $L_{2}(p)$, respectively, then

(1) If $\operatorname{Exp}\left(L_{1}(p)\right)<\operatorname{Exp}\left(L_{2}(p)\right)$, then $L_{1}(p) \prec \operatorname{Exp} L_{2}(p)$;

(2) If $\operatorname{Exp}\left(L_{1}(p)\right)=\operatorname{Exp}\left(L_{2}(p)\right)$, then $\left\{\begin{array}{l}\text { if } \operatorname{Var}\left(L_{1}(p)\right)>\operatorname{Var}\left(L_{2}(p)\right) \text {, then } L_{1}(p) \prec_{\operatorname{Exp} / \operatorname{Var}} L_{2}(p) \\ \text { if } \operatorname{Var}\left(L_{1}(p)\right)=\operatorname{Var}\left(L_{2}(p)\right) \text {, then } L_{1}(p) \sim_{\operatorname{Exp} / \operatorname{Var}} L_{2}(p)\end{array}\right.$. 
For example, given three normalized PLTSs $L_{1}(p)=\left\{l_{4}(0.8), l_{5}(0.2)\right\}, L_{2}(p)=\left\{l_{4}(1.0)\right\}$ and $L_{3}(p)=\left\{l_{3}(0.3), l_{4}(0.4), l_{5}(0.3)\right\}$, we need to compare their magnitude. Using the above comparison method of PLTSs, it is easy to obtain that

$$
\begin{aligned}
& \operatorname{Exp}\left(L_{1}(p)\right)=4.2, \operatorname{Exp}\left(L_{2}(p)\right)=4.0, \operatorname{Exp}\left(L_{3}(p)\right)=4.0 \\
& \operatorname{Var}\left(L_{1}(p)\right)=0.16, \operatorname{Var}\left(L_{2}(p)\right)=0.0, \operatorname{Var}\left(L_{3}(p)\right)=0.6 .
\end{aligned}
$$

According to the above comparison law, it is easily observed that $L_{1}(p) \succ_{\operatorname{Exp}} L_{2}(p) \succ_{\operatorname{Exp} / \operatorname{Var}} L_{3}(p)$, which is reasonable based on intuition.

Theorem 1. Given a PLTS $L(p)$, let $\bar{L}(p)$ be the normalized form of $L(p)$; then the following statements hold:

(1) $\operatorname{Exp}(L(p))=\operatorname{Exp}(\bar{L}(p))$;

(2) $\operatorname{Var}(L(p))=\operatorname{Var}(\bar{L}(p))$;

(3) if $L_{1}(p) \prec_{\text {Exp/Var }} L_{2}(p)$, then $\bar{L}_{1}(p) \prec_{\text {Exp } / \operatorname{Var}} \bar{L}_{2}(p)$.

The proof of Theorem 1 is straightforward. According to the definitions of the expectation and variance of PLTSs, it is easy to show that statements (1) and (2) in Theorem 1 hold. Based on statements (1) and (2) in Theorem 1, statement (3) in Theorem 1 holds apparently.

Using the above comparison method of PLTSs, the positive ideal solution $\left(L_{j(k)}(p)\right)^{+}$among all alternatives over the sub-criterion $c_{j(k)}\left(k=1,2, \cdots, \# c_{j}\right)$ under the main-criterion $c_{j}(j=1,2, \cdots, n)$ is determined as follows:

$$
\left(L_{j(k)}(p)\right)^{+}=\max _{i=1}^{m}\left(L_{i j(k)}(p)\right), k=1,2, \cdots, \# c_{j}, j=1,2,3,4
$$

and the negative ideal solution $\left(L_{j(k)}(p)\right)^{-}$is identified as follows:

$$
\left(L_{j(k)}(p)\right)^{-}=\min _{i=1}^{m}\left(L_{i j(k)}(p)\right), k=1,2, \cdots, \# c_{j}, j=1,2,3,4
$$

Therefore, the probabilistic linguistic positive ideal solution for this kind of probabilistic linguistic MCDM problem is denoted by:

$$
F^{+}=\left(\begin{array}{cccc}
\left(L_{1(1)}(p)\right)^{+} & \left(L_{1(2)}(p)\right)^{+} & \ldots & \left(L_{1(\# c 1)}(p)\right)^{+} \\
\left(L_{2(1)}(p)\right)^{+} & \left(L_{2(2)}(p)\right)^{+} & \ldots & \left(L_{2(\# c 2)}(p)\right)^{+} \\
\left(L_{3(1)}(p)\right)^{+} & \left(L_{3(2)}(p)\right)^{+} & \ldots & \left(L_{3(\# c 3)}(p)\right)^{+} \\
\left(L_{4(1)}(p)\right)^{+} & \left(L_{4(2)}(p)\right)^{+} & \ldots & \left(L_{4(\# c 4)}(p)\right)^{+}
\end{array}\right)
$$

and the probabilistic linguistic negative ideal solution is represented by:

$$
F^{-}=\left(\begin{array}{cccc}
\left(L_{1(1)}(p)\right)^{-} & \left(L_{1(2)}(p)\right)^{-} & \cdots & \left(L_{1(\# c 1)}(p)\right)^{-} \\
\left(L_{2(1)}(p)\right)^{-} & \left(L_{2(2)}(p)\right)^{-} & \cdots & \left(L_{2(\# c 2)}(p)\right)^{-} \\
\left(L_{3(1)}(p)\right)^{-} & \left(L_{3(2)}(p)\right)^{-} & \cdots & \left(L_{3(\# c 3)}(p)\right)^{-} \\
\left(L_{4(1)}(p)\right)^{-} & \left(L_{4(2)}(p)\right)^{-} & \cdots & \left(L_{4(\# c 4)}(p)\right)^{-}
\end{array}\right)
$$

\subsection{Measuring the Closeness Indices of Alternatives to the Ideal solutions}

Next, the distance measure of PLTSs developed by Zhang [58] is used to measure the closeness index to the ideal solution. Before that, we need to defuzzy the weights of the main-criteria and the weights of their sub-criteria because they are represented by PLTSs in our work. To this end, we first develop a defuzzification function of PLTSs. 
Definition 8. Given a set of PLTSS $\left\{L_{1}(p), L_{2}(p), \cdots, L_{m}(p)\right\}$ based on the LTS $L=\left\{l_{\sigma} \mid \sigma \in \Gamma\right\}$, the defuzzification function value of $L_{i}(p)(i=1,2, \cdots, m)$ is provided as follows:

$$
f\left(L_{i}(p)\right)=\partial \frac{\operatorname{Exp}\left(L_{i}(p)\right)-\min _{i=1}^{m} \operatorname{Exp}\left(L_{i}(p)\right)}{\max _{i=1}^{m} \operatorname{Exp}\left(L_{i}(p)\right)-\min _{i=1}^{m} \operatorname{Exp}\left(L_{i}(p)\right)}+(1-\partial) \frac{\max _{i=1}^{m} \operatorname{Var}\left(L_{i}(p)\right)-\operatorname{Var}_{i=1}^{m}\left(L_{i}(p)\right)}{\max _{i=1}^{m} \operatorname{Var}\left(L_{i}(p)\right)-\min _{i=1}^{m} \operatorname{Var}\left(L_{i}(p)\right)}
$$

where $\operatorname{Exp}\left(L_{i}(p)\right)$ is the expectation values of $L_{i}(p)(i=1,2, \cdots, m)$ and $\operatorname{Var}\left(L_{i}(p)\right)$ is the variance values of $L_{i}(p)(i=1,2, \cdots, m)$, and the parameter $\partial$ is to balance the expectation values and the variance values in decision making process, which should be bigger than 0.5 according to the developed comparison law of PLTSs.

Furthermore, the normalized defuzzification values of the weights of the main-criteria $w\left(c_{j}\right)$ and the sub-criteria $w\left(c_{j(k)}\right)$ are obtained as follows:

$$
\bar{f}\left(w\left(c_{j(k)}\right)\right)=\frac{f\left(w\left(c_{j k}\right)\right)}{\sum_{k=1}^{\# c_{j}} f\left(w\left(c_{j k}\right)\right)}, \bar{f}\left(w\left(c_{j}\right)\right)=\frac{f\left(w\left(c_{j}\right)\right)}{\sum_{j=1}^{4} f\left(w\left(c_{j}\right)\right)}
$$

As a result, the overall weight of the sub-criterion $c_{j(k)}$, which is denoted by $\omega_{i j}$, is the product of the normalized defuzzification values of the weight of this sub-criterion $c_{j(k)}$ and the normalized defuzzification values of the weight of the corresponding main-criterion $c_{j}$.

$$
\omega_{i j}=\bar{f}\left(w\left(c_{j(k)}\right)\right) \times \bar{f}\left(w\left(c_{j}\right)\right)
$$

Then, the probabilistic linguistic group utility measure of the alternative $a_{i}(i=1,2, \cdots, m)$ is defined by the following equation:

$$
P L S_{i}=\sum_{j=1}^{n} \sum_{k=1}^{\# c_{j}} \omega_{i j} \frac{d\left(\left(L_{j(k)}(p)\right)^{+}, L_{i j(k)}(p)\right)}{d\left(\left(L_{j(k)}(p)\right)^{+},\left(L_{j(k)}(p)\right)^{-}\right)}
$$

Furthermore, the probabilistic linguistic individual regret measure of the alternative $a_{i}(i=1,2, \cdots, m)$ is introduced by the following equation:

$$
P L R_{i}=\max _{j=1 k=1}^{n} \# c_{j} \omega_{i j} \frac{d\left(\left(L_{j(k)}(p)\right)^{+}, L_{i j(k)}(p)\right)}{d\left(\left(L_{j(k)}(p)\right)^{+},\left(L_{j(k)}(p)\right)^{-}\right)}
$$

According to the idea of the classical VIKOR method, the compromise solution is usually a maximum group utility for the majority and a minimum individual regret for the opponent, simultaneously. To this end, the compromise measure of the alternative $a_{i}(i=1,2, \cdots, m)$ is defined as below:

$$
P L Q_{i}=\eta \frac{S_{i}-\min _{i=1}^{m} S_{i}}{\max _{i=1}^{m} S_{i}-\min _{i=1}^{m} S_{i}}+(1-\eta) \frac{R_{i}-\min _{i=1}^{m} R_{i}}{\max _{i=1}^{m} R_{i}-\min _{i=1}^{m} R_{i}}
$$

where the parameter $\eta$ is the weight of the strategy of the majority of criteria or the maximum overall utility, and is usually taken as 0.5 .

According to the decreasing order of the values of $P L S_{i}, P L R_{i}, P L Q_{i}(i=1,2, \cdots, m)$, three ranking lists of alternatives are obtained. The compromise solution for the MCDM problem is the alternative $a_{\sigma(1)}$ (it is the alternative with the first position in the ranking list derived by $\left.P L Q_{i}(i=1,2, \cdots, m)\right)$ if the following two conditions are satisfied. 
Condition $C_{1} \cdot \operatorname{PLQ}\left(a_{\sigma(2)}\right)-P L Q\left(a_{\sigma(1)}\right) \geq \frac{1}{m-1}$

Condition $C_{2}$. The alternative $a_{\sigma(1)}$ is also the alternative with the first position in the ranking lists derived by $\operatorname{PLS}_{i}(i=1,2, \cdots, m)$ and/or $\operatorname{PLR}_{i}(i=1,2, \cdots, m)$.

It is common that these two conditions are not usually satisfied simultaneously in the practical MCDM process. If Condition $C_{1}$ is not satisfied, the set of alternatives $\left\{a_{\sigma(1)}, a_{\sigma(2)}, \cdots, a_{\sigma(\mu)}\right\}$ is the compromise solution in which the maximum value of $\mu$ is determined by the following equation: $P L Q\left(a_{\sigma(\mu)}\right)-P L Q\left(a_{\sigma(1)}\right)<1 /(m-1)$; and if Condition $C_{2}$ is not satisfied, then the set of alternatives $\left\{a_{\sigma(1)}, a_{\sigma(2)}\right\}$ is the set of compromise solutions.

\subsection{Procedures for the Developed Method}

Based on the above analysis, the schematic diagram of the proposed method for solving the MCDM problem with PLTSs is provided in Figure 2, and the decision procedures of the proposed method can be summarized as follows:

Step 1. Formulate the MCDM problem, identify the probabilistic linguistic decision matrix, and determine the probabilistic linguistic weights of the main-criteria and sub-criteria.

Step 2. Determine the probabilistic linguistic positive ideal solution and the probabilistic linguistic negative ideal solution by employing Equation (16) and Equation (17), respectively.

Step 3. Calculate the overall weight of each sub-criterion by using Equation (20).

Step 4. Compute the probabilistic linguistic group utility measures of alternatives by using Equation (21).

Step 5. Calculate the probabilistic linguistic individual regret measures of all alternatives by using Equation (22).

Step 6. Calculate the compromise measures of alternatives by employing Equation (23).

Step 7. Identify the compromise solution(s) according to the values of $P L S_{i}, P L R_{i}, P L Q_{i}$.
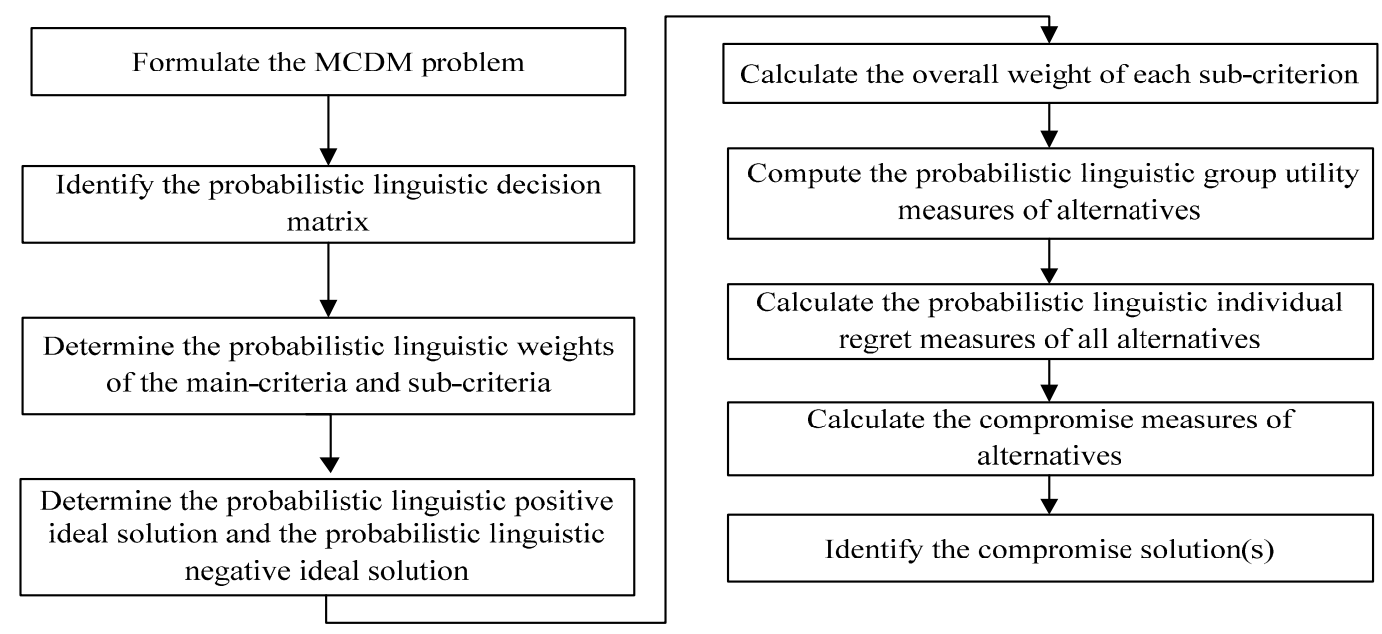

Figure 2. Schematic diagram of the proposed probabilistic linguistic VIKOR technique.

\section{A Case Study for the Evaluation of Green Supply Chain Initiatives}

In this section, a real-world MCDM problem involved with the selection of an appropriate time window for a fashion company to implement green raw material is introduced to demonstrate the decision making process and usefulness of the developed probabilistic linguistic VIKOR approach. 


\subsection{Description}

To improve saleability and secure future growth in the wide market, more and more fashion retail firms intend to employ new green materials in their products. The use of new green materials in turn requires changes in firms' operational capabilities and resources that may have an adverse effect on firms' operations performance [2]. Thus, the firms need to evaluate their performances carefully when implementing GSC initiatives. In this section, we consider a real-life MCDM problem involved with the selection of an appropriate time window for a fashion company to implement green raw material. An expert panel was formed to conduct the assessment which is concerned with four potential implementation time windows in terms of the readiness to implement green raw material, i.e., Implement now $\left(a_{1}\right)$, Implement in 4 months $\left(a_{2}\right)$, Implement in 8 months $\left(a_{3}\right)$, and Implement in 12 months $\left(a_{4}\right)$. Through the expert panel discussion, the detailed sub-criteria under the four main-criteria were identified in Table 2 [2]. Meanwhile, all experts individually and anonymously provide their assessments on the importance of the main-criteria and the sub-criteria by using the LTS with the granularity $g(1)=5 L^{(5)}=\left\{l_{1}^{(5)}:\right.$ very low, $l_{2}^{(5)}:$ low, $l_{4}^{(5)}:$ middle, $l_{4}^{(5)}:$ high, $l_{5}^{(5)}:$ very high $\}$. According to the assessments provided anonymously by all experts concerning the weights of the main-criteria and the sub-criteria which are omitted here, the collective assessments for the expert panel concerning the weights of the main-criteria and the sub-criteria can be modeled by using PLTSs and are listed in Table 2. For instance, the evaluation value $\left\{l_{2}^{(5)}(0.2), l_{3}^{(5)}(0.8)\right\}$ in Table 2 means that $20 \%$ experts from the expert panel employ " $l_{2}^{(5)}: l o w$ " from the LTS $L^{(5)}$ to express the importance of the main-criterion " $c_{3}$ Logistics" and $80 \%$ experts employ " $l_{3}^{(5)}:$ middle" to express the importance of the main-criterion " $\mathrm{c}_{3}$ Logistics".

Table 2. The weights of the main-criteria and the corresponding sub-criteria.

\begin{tabular}{|c|c|c|c|}
\hline Main-Criteria & Weights of Main-Criteria & Sub-Criteria & Weights of Sub-Criteria \\
\hline$c_{1}$ Manufacturing & $\left\{l_{3}^{(5)}(0.5), l_{4}^{(5)}(0.5)\right\}$ & $\begin{array}{c}\mathrm{c}_{1(1)} \text { Processes } \\
\mathrm{c}_{1(2)} \text { Technical capability } \\
\mathrm{c}_{1(3)} \text { Innovation capability } \\
\mathrm{c}_{1(4)} \text { Production capacity }\end{array}$ & $\begin{aligned} & \left\{l_{4}^{(5)}(0.8), l_{5}^{(5)}(0.2)\right\} \\
& \left\{l_{3}^{(5)}(0.2), l_{4}^{(5)}(0.8)\right\} \\
\left\{l_{3}^{(5)}\right. & \left.(0.3), l_{4}^{(5)}(0.4), l_{5}^{(5)}(0.3)\right\} \\
& \left\{l_{3}^{(5)}(0.5), l_{4}^{(5)}(0.5)\right\}\end{aligned}$ \\
\hline$c_{2}$ Purchasing & $\left\{l_{3}^{(5)}(1.0)\right\}$ & $\begin{array}{c}c_{2(1)} \text { Raw material availability } \\
c_{2(2)} \text { Suppliers } \\
c_{2(3)} \text { Inventory level } \\
c_{2(4)} \text { Assurance of supply }\end{array}$ & $\begin{array}{c}\left\{l_{4}^{(5)}(0.8), l_{5}^{(5)}(0.2)\right\} \\
\left\{l_{3}^{(5)}(0.2), l_{4}^{(5)}(0.8)\right\} \\
\left\{l_{4}^{(5)}(1.0)\right\} \\
\left\{l_{3}^{(5)}(0.3), l_{4}^{(5)}(0.4), l_{5}^{(5)}(0.3)\right\}\end{array}$ \\
\hline$c_{3}$ Logistics & $\left\{l_{2}^{(5)}(0.2), l_{3}^{(5)}(0.8)\right\}$ & $\begin{array}{c}c_{3(1)} \text { Inbound logistics } \\
c_{3(2)} \text { Outbound logistics } \\
c_{3(3)} \text { Packaging } \\
c_{3(4)} \text { Shipment accuracy }\end{array}$ & $\begin{array}{c}\left\{l_{3}^{(5)}(0.2), l_{4}^{(5)}(0.8)\right\} \\
\left\{l_{4}^{(5)}(1.0)\right\} \\
\left\{l_{4}^{(5)}(0.8), l_{5}^{(5)}(0.2)\right\} \\
\left\{l_{3}^{(5)}(0.3), l_{4}^{(5)}(0.4), l_{5}^{(5)}(0.3)\right\}\end{array}$ \\
\hline $\mathrm{c}_{4}$ Marketing & $\left\{l_{3}^{(5)}(0.3), l_{4}^{(5)}(0.4), l_{5}^{(5)}(0.3)\right\}$ & $\begin{array}{c}\mathrm{c}_{4(1)} \text { Salability } \\
\mathrm{c}_{4(2)} \text { Growth } \\
\mathrm{c}_{4(3)} \text { Marketability } \\
\mathrm{c}_{4(4)} \text { Customer service }\end{array}$ & $\begin{array}{c}\left\{l_{3}^{(5)}(0.5), l_{4}^{(5)}(0.5)\right\} \\
\left\{l_{3}^{(5)}(1.0)\right\} \\
\left\{l_{3}^{(5)}(0.3), l_{4}^{(5)}(0.4), l_{5}^{(5)}(0.3)\right\} \\
\left\{l_{2}^{(5)}(0.2), l_{3}^{(5)}(0.8)\right\}\end{array}$ \\
\hline
\end{tabular}

Then, these four implementation time windows were evaluated with respect to the detailed sub-criteria in terms of the readiness to implement green raw material. It is assumed that (1) the assessments of the alternative time windows for the sub-criteria $c_{1(1)}, c_{2(1)}, c_{3(1)}$ and $c_{4(1)}$ are based on the LTS with the granularity $\mathrm{g}(1)=9$; (2) the assessments of the alternative time windows for the sub-criteria $c_{1(2)}, c_{2(2)}, c_{3(2)}, c_{4(2)}, c_{1(3)}, c_{2(3)}, c_{3(3)}$ and $c_{4(3)}$ are based on the LTS with the granularity $\mathrm{g}(1)=7$; (3) the assessments of the alternative time windows for the sub-criteria $c_{1(4)}, c_{2(4)}, c_{3(4)}$ and $c_{4(4)}$ are based on the LTS with the granularity $g(1)=5$. These assessments provided by the expert panel are modeled by using PLTSs with multi-granularity LTS and are listed in Table 3. 
Table 3. The probabilistic linguistic evaluation results of alternatives.

\begin{tabular}{|c|c|c|c|c|}
\hline \multirow{2}{*}{ Criteria } & \multicolumn{4}{|c|}{ The implementation time windows } \\
\hline & Implement Now $a_{1}$ & $\begin{array}{l}\text { Implement in } 4 \text { Months } \\
a_{2}\end{array}$ & $\begin{array}{c}\text { Implement in } 8 \text { Months } \\
a_{3}\end{array}$ & Implement in 12 Months $\mathrm{a}_{4}$ \\
\hline$c_{1(1)}$ & $\left\{l_{5}^{(9)}, l_{6}^{(9)}\right\}$ & $\left\{l_{6}^{(9)}, l_{7}^{(9)}\right\}$ & $\left\{l_{5}^{(9)}, l_{6}^{(9)}\right\}$ & $\left\{l_{4}^{(9)}, l_{5}^{(9)}, l_{6}^{(9)}\right\}$ \\
\hline$c_{1(2)}$ & $\left\{l_{4}^{(7)}(1.0)\right\}$ & $\left\{l_{4}^{(7)}(1.0)\right\}$ & $\left\{l_{5}^{(7)}(0.2), l_{6}^{(7)}(0.8)\right\}$ & $\left\{l_{5}^{(7)}(0.2), l_{6}^{(7)}(0.8)\right\}$ \\
\hline$c_{1(3)}$ & $\left\{l_{5}^{(7)}\right\}$ & $\left\{l_{5}^{(7)}, l_{6}^{(7)}\right\}$ & $\left\{l_{5}^{(7)}\right\}$ & $\left\{l_{4}^{(7)}, l_{5}^{(7)}\right\}$ \\
\hline$c_{1(4)}$ & $\left\{l_{2}^{(5)}(0.9)\right\}$ & $\left\{l_{4}^{(5)}(0.6), l_{5}^{(5)}(0.2)\right\}$ & $\left\{l_{3}^{(5)}(0.2), l_{4}^{(5)}(0.4), l_{5}^{(5)}(0.2)\right\}$ & $\left\{l_{2}^{(5)}(0.2), l_{3}^{(5)}(0.3), l_{4}^{(5)}(0.3)\right\}$ \\
\hline$c_{2(1)}$ & $\left\{l_{4}^{(9)}, l_{5}^{(9)}, l_{6}^{(9)}\right\}$ & $\left\{l_{5}^{(9)}, l_{6}^{(9)}, l_{7}^{(9)}\right\}$ & $\left\{l_{6}^{(9)}, l_{7}^{(9)}\right\}$ & $\left\{l_{4}^{(9)}, l_{5}^{(9)}\right\}$ \\
\hline$c_{2(2)}$ & $\left\{l_{3}^{(7)}(0.2), l_{4}^{(7)}(0.4), l_{5}^{(7)}(0.4)\right\}$ & $\left\{l_{4}^{(7)}(0.2), l_{5}^{(7)}(0.5), l_{6}^{(7)}(0.3)\right\}$ & $\left\{l_{4}^{(7)}(0.2), l_{5}^{(7)}(0.5), l_{6}^{(7)}(0.3)\right\}$ & $\left\{l_{4}^{(7)}(0.7), l_{5}^{(7)}(0.3)\right\}$ \\
\hline$c_{2(3)}$ & $\left\{l_{4}^{(7)}, l_{5}^{(7)}\right\}$ & $\left\{l_{3}^{(7)}, l_{4}^{(7)}, l_{5}^{(7)}\right\}$ & $\left\{l_{5}^{(7)}, l_{6}^{(7)}\right\}$ & $\left\{l_{3}^{(7)}, l_{4}^{(7)}\right\}$ \\
\hline$c_{2(4)}$ & $\left\{l_{2}^{(5)}(0.3), l_{3}^{(5)}(0.4), l_{4}^{(5)}(0.3)\right\}$ & $\left\{l_{2}^{(5)}(0.4), l_{3}^{(5)}(0.4), l_{4}^{(5)}(0.2)\right\}$ & $\left\{l_{3}^{(5)}(0.4), l_{4}^{(5)}(0.6)\right\}$ & $\left\{l_{1}^{(5)}(0.2), l_{2}^{(5)}(0.2), l_{3}^{(5)}(0.2), l_{4}^{(5)}(0.4)\right\}$ \\
\hline$c_{3(1)}$ & $\left\{l_{5}^{(9)}\right\}$ & $\left\{l_{6}^{(9)}, l_{7}^{(9)}\right\}$ & $\left\{l_{6}^{(9)}, l_{7}^{(9)}, l_{8}^{(9)}, l_{9}^{(9)}\right\}$ & $\left\{l_{4}^{(9)}\right\}$ \\
\hline$c_{3(2)}$ & $\left\{l_{5}^{(7)}(1.0)\right\}$ & $\left\{l_{6}^{(7)}(1.0)\right\}$ & $\left\{l_{6}^{(7)}(0.8), l_{7}^{(7)}(0.2)\right\}$ & $\left\{l_{3}^{(7)}(0.3), l_{4}^{(7)}(0.7)\right\}$ \\
\hline$c_{3(3)}$ & $\left\{l_{4}^{(7)}, l_{5}^{(7)}, l_{6}^{(7)}\right\}$ & $\left\{l_{4}^{(7)}, l_{5}^{(7)}\right\}$ & $\left\{l_{6}^{(7)}\right\}$ & $\left\{l_{5}^{(7)}\right\}$ \\
\hline$c_{3(4)}$ & $\left\{l_{3}^{(5)}(0.2), l_{4}^{(5)}(0.4), l_{5}^{(5)}(0.4)\right\}$ & $\left\{l_{3}^{(5)}(0.6), l_{4}^{(5)}(0.4)\right\}$ & $\begin{array}{l}\left\{l_{2}^{(5)}(0.2), l_{3}^{(5)}(0.3)\right. \\
\left.l_{4}^{(5)}(0.3), l_{5}^{(5)}(0.2)\right\}\end{array}$ & $\begin{array}{l}\left\{l_{1}^{(5)}(0.1), l_{2}^{(5)}(0.2)\right. \\
\left.l_{3}^{(5)}(0.4), l_{4}^{(5)}(0.3)\right\}\end{array}$ \\
\hline$c_{4(1)}$ & $\left\{l_{4}^{(9)}, l_{5}^{(9)}\right\}$ & $\left\{l_{5}^{(9)}, l_{6}^{(9)}, l_{7}^{(9)}, l_{8}^{(9)}\right\}$ & $\left\{l_{6}^{(9)}\right\}$ & $\left\{l_{3}^{(9)}, l_{4}^{(9)}, l_{5}^{(9)}, l_{6}^{(9)}\right\}$ \\
\hline$c_{4(2)}$ & $\left\{l_{4}^{(7)}(0.5), l_{5}^{(7)}(0.3), l_{6}^{(7)}(0.2)\right\}$ & $\left\{l_{5}^{(7)}(0.6), l_{6}^{(7)}(0.4)\right\}$ & $\left\{l_{6}^{(7)}(1.0)\right\}$ & $\left\{l_{6}^{(7)}(1.0)\right\}$ \\
\hline$c_{4(3)}$ & $\left\{l_{3}^{(7)}, l_{4}^{(7)}, l_{5}^{(7)}\right\}$ & $\left\{l_{5}^{(7)}\right\}$ & $\left\{l_{4}^{(7)}, l_{5}^{(7)}, l_{6}^{(7)}\right\}$ & $\left\{l_{3}^{(7)}, l_{4}^{(7)}, l_{5}^{(7)}\right\}$ \\
\hline$c_{4(4)}$ & $\left\{l_{2}^{(5)}(0.2), l_{3}^{(5)}(0.8)\right\}$ & $\left\{l_{3}^{(5)}(0.4), l_{4}^{(5)}(0.4), l_{5}^{(5)}(0.2)\right\}$ & $\left\{l_{3}^{(5)}(0.5), l_{4}^{(5)}(0.5)\right\}$ & $\left\{l_{2}^{(5)}(0.3), l_{3}^{(5)}(0.3), l_{4}^{(5)}(0.4)\right\}$ \\
\hline
\end{tabular}

\subsection{The Decision Making Processes}

In this section, the developed probabilistic linguistic VIKOR approach is employed to assist the company in selecting an appropriate time window to implement the green raw material. Firstly, the probabilistic linguistic positive ideal solution and negative ideal solution are determined by employing Equations (16) and (17), respectively. These results are illustrated in Table 4.

Table 4. Probabilistic linguistic positive ideal solutions and negative ideal solutions.

\begin{tabular}{ccc}
\hline Sub-Criteria & Positive Ideal Solutions & Negative Ideal Solutions \\
\hline$c_{1(1)}$ & $\left\{l_{6}^{(9)}, l_{7}^{(9)}\right\}$ & $\left\{l_{4}^{(9)}, l_{5}^{(9)}, l_{6}^{(9)}\right\}$ \\
$c_{1(2)}$ & $\left\{l_{5}^{(7)}(0.2), l_{6}^{(7)}(0.8)\right\}$ & $\left\{l_{4}^{(7)}(1.0)\right\}$ \\
$c_{1(3)}$ & $\left\{l_{5}^{(7)}, l_{6}^{(7)}\right\}$ & $\left\{l_{4}^{(7)}, l_{5}^{(7)}\right\}$ \\
$c_{1(4)}$ & $\left\{l_{4}^{(5)}(0.6), l_{5}^{(5)}(0.2)\right\}$ & $\left\{l_{2}^{(5)}(0.9)\right\}$ \\
$c_{2(1)}$ & $\left\{l_{6}^{(9)}, l_{7}^{(9)}\right\}$ & $\left\{l_{4}^{(9)}, l_{5}^{(9)}\right\}$ \\
$c_{2(2)}$ & $\left\{l_{4}^{(7)}(0.2), l_{5}^{(7)}(0.5), l_{6}^{(7)}(0.3)\right\}$ & $\left\{l_{3}^{(7)}(0.2), l_{4}^{(7)}(0.4), l_{5}^{(7)}(0.4)\right\}$ \\
$c_{2(3)}$ & $\left\{l_{5}^{(7)}, l_{6}^{(7)}\right\}$ & $\left\{l_{3}^{(7)}, l_{4}^{(7)}\right\}$ \\
$c_{2(4)}$ & $\left\{l_{3}^{(5)}(0.4), l_{4}^{(5)}(0.6)\right\}$ & $\left\{l_{4}^{(9)}\right\}$ \\
$c_{3(1)}$ & $\left\{l_{6}^{(9)}, l_{7}^{(9)}, l_{8}^{(9)}, l_{9}^{(9)}\right\}$ & $\left\{l_{1}^{(5)}(0.2), l_{2}^{(5)}(0.2), l^{(5)}(0.2), l_{4}^{(5)}(0.4)\right\}$ \\
$c_{3(2)}$ & $\left\{l_{6}^{(7)}(0.8), l_{7}^{(7)}(0.2)\right\}$ & $\left\{l_{4}^{(7)}, l_{5}^{(7)}\right\}$ \\
$c_{3(3)}$ & $\left\{l_{6}^{(7)}\right\}$ & $\{(0.7)\}$ \\
$c_{3(4)}$ & $\left\{l_{3}^{(5)}(0.2), l_{4}^{(5)}(0.4), l_{5}^{(5)}(0.4)\right\}$ & $\left\{l_{1}^{(5)}(0.1), l_{2}^{(5)}(0.2), l_{3}^{(5)}(0.4), l_{4}^{(5)}(0.3)\right\}$ \\
$c_{4(1)}$ & $\left\{l_{5}^{(9)}, l_{6}^{(9)}, l_{7}^{(9)}, l_{8}^{(9)}\right\}$ & $\left\{l_{4}^{(9)}, l_{5}^{(9)}\right\}$ \\
$c_{4(2)}$ & $\left\{l_{6}^{(7)}(1.0)\right\}$ & $\left\{l_{4}^{(7)}(0.5), l_{5}^{(7)}(0.3), l_{6}^{(7)}(0.2)\right\}$ \\
$c_{4(3)}^{(7)}$ & $\left\{l_{4}^{(7)}, l_{5}^{(7)}, l_{6}^{(7)}\right\}$ & $\left\{l_{3}^{(7)}, l_{4}^{(7)}, l_{5}^{(7)}\right\}$ \\
$\mathrm{c}_{4(4)}$ & $\left\{l_{3}^{(5)}(0.4), l_{4}^{(5)}(0.4), l_{5}^{(5)}(0.2)\right\}$ & $\left\{l_{2}^{(5)}(0.2), l_{3}^{(5)}(0.8)\right\}$ \\
\hline
\end{tabular}


Then, the normalized defuzzification values of the weights of the main-criteria and the corresponding sub-criteria are obtained by using Equation (19). These results are illustrated in Table 5. Furthermore, the overall weights of the sub-criteria under each main-criterion are obtained by employing Equation (20) and are also shown in Table 5.

Table 5. The defuzzification values of the main-criteria weights and the sub-criteria weights.

\begin{tabular}{|c|c|c|c|c|}
\hline Main-Criteria & $\begin{array}{c}\text { Defuzzification Values } \\
\text { of Main-Criteria } \\
\text { Weights }\end{array}$ & Sub-Criteria & $\begin{array}{c}\text { Defuzzification } \\
\text { Values of Sub-Criteria } \\
\text { Weights }\end{array}$ & $\begin{array}{l}\text { The Overall } \\
\text { Weights of } \\
\text { Sub-Criteria }\end{array}$ \\
\hline \multirow{4}{*}{$c_{1}$} & \multirow{4}{*}{0.2951} & $\mathrm{c}_{1(1)}$ & 0.4160 & 0.1228 \\
\hline & & $c_{1(2)}$ & 0.2734 & 0.0807 \\
\hline & & $c_{1(3)}$ & 0.1783 & 0.0526 \\
\hline & & $\mathrm{c}_{1(4)}$ & 0.1324 & 0.0391 \\
\hline \multirow{4}{*}{$\mathrm{c}_{2}$} & \multirow{4}{*}{0.2530} & $c_{2(1)}$ & 0.4085 & 0.1033 \\
\hline & & $c_{2(2)}$ & 0.1341 & 0.0339 \\
\hline & & $c_{2(3)}$ & 0.3201 & 0.0810 \\
\hline & & $c_{2(4)}$ & 0.1372 & 0.0347 \\
\hline \multirow{4}{*}{$c_{3}$} & \multirow{4}{*}{0.1484} & $c_{3(1)}$ & 0.1341 & 0.0199 \\
\hline & & $c_{3(2)}$ & 0.3201 & 0.0475 \\
\hline & & $c_{3(3)}$ & 0.4085 & 0.0606 \\
\hline & & $c_{3(4)}$ & 0.1372 & 0.0204 \\
\hline \multirow{4}{*}{$\mathrm{c}_{4}$} & \multirow{4}{*}{0.3035} & $\mathrm{c}_{4(1)}$ & 0.2951 & 0.0896 \\
\hline & & $\mathrm{c}_{4(2)}$ & 0.2530 & 0.0768 \\
\hline & & $\mathrm{c}_{4(3)}$ & 0.3035 & 0.0921 \\
\hline & & $\mathrm{c}_{4(4)}$ & 0.1484 & 0.0450 \\
\hline
\end{tabular}

Afterwards, the probabilistic linguistic group utility measures of four alternative implementation time windows are calculated by using Equation (21) as below:

$$
P L S_{1}=0.7440, P L S_{2}=0.5204, P L S_{3}=0.2626, P L S_{4}=0.6742 \text {, }
$$

and the probabilistic linguistic individual regret measures of these four alternative implementation time windows are computed by using Equation (22) as follows:

$$
P L R_{1}=0.0921, P L R_{2}=0.1535, P L R_{3}=0.0898, P L R_{4}=0.1228 \text {. }
$$

Using Equation (23), the probabilistic linguistic compromise measures of these four alternative implementation time windows are calculated as follows:

$$
P L Q_{1}=0.5180, P L Q_{2}=0.7678, P L Q_{3}=0.0000, P L Q_{4}=0.6861
$$

According to the decreasing order of the values of $P L S_{i}, P L R_{i}, P L Q_{i}(i=1,2,3,4)$, three ranking lists of these four alternative implementation time windows are obtained as follows:

$$
a_{3} \succ_{P L S} a_{2} \succ_{P L S} a_{4} \succ_{P L S} a_{1}, a_{3} \succ_{P L R} a_{1} \succ_{P L R} a_{4} \succ_{P L R} a_{2}, a_{3} \succ_{P L Q} a_{1} \succ_{P L Q} a_{4} \succ_{P L Q} a_{2} .
$$

Obviously, the compromise solution for the above assessment problem is alternative $a_{3}$ (i.e., Implement in 8 months) since it satisfies the following two conditions: (1) condition $C_{1}$, i.e., $P L Q\left(a_{3}\right)-P L Q\left(a_{1}\right)=0.5180 \geq \frac{1}{4-1}(=0.3333)$; (2) condition $C_{2}$, i.e., alternative $a_{3}$ is also the alternative with the first position in the ranking lists derived by $P L R_{i}(i=1,2,3,4)$. 


\subsection{Discussion}

The results derived for the developed probabilistic linguistic VIKOR technique show that implementing the green raw material in 8 months $\left(a_{3}\right)$ is the appropriate time window for the fashion company and should be recommended among the four possible time windows. The main reason is that there are potential gaps in capability and resources in its supply chain in order to successfully implement the green raw material now [2]. It is easily noticed that compared with implementing now $\left(a_{1}\right)$, the company has made full preparations in terms of manufacturing processes, production capacity, and technical and innovation capabilities when implementing green raw material in eight months, and based on a comparison with implementing in twelve months $\left(a_{4}\right)$, the company has marketing advantages over its rival competitors because few competitors have already launched similar green initiatives. Therefore, the result obtained by the probabilistic linguistic VIKOR method is reasonable. Comparing the previous studies [2,12] on the evaluation of GSC initiatives, the developed probabilistic linguistic VIKOR technique allows the evaluators to employ PLTS to express the imprecise performances of the GSC initiatives with respect to various criteria, which greatly improves the elicitation of linguistic information. Moreover, it presents a probabilistic linguistic compromise solution which is a maximum probabilistic linguistic group utility for the majority and a minimum probabilistic linguistic individual regret for the opponent. Although the proposed probabilistic linguistic VIKOR technique is used in this paper to assist a fashion retail company for selecting an appropriate time window to implement green raw material, this proposed technique can also be used by different companies in other industry sections, as it is extremely flexible and can be reduced into various special models according to the different actual needs.

\section{Conclusions}

The real-world GSC management problems in which the decision data are represented by PLTSs are more and more common nowadays. To adequately deal with this kind of GSC management problem with PLTSs, in this paper, we have developed a new probabilistic linguistic VIKOR method. Using this developed method, the managers of a fashion retail firm have successfully selected a suitable time window to implement green raw material in order to achieve the goals of sustainable economic and environmental protection. The main contributions of this paper are summarized as follows: (1) a new comparison method of PLTSs has been presented to effectively identify the ideal solutions for the probabilistic linguistic MCDM problems; (2) a new defuzzification function of PLTSs has been proposed to fully take into account the weights of criteria under probabilistic linguistic contexts; (3) a new probabilistic linguistic VIKOR approach has been developed to effectively evaluate various challenges that the firms usually face when implementing GSC initiatives.

Nevertheless, this study also contains several limitations which may serve as suggestions for further research. First, we assumed that all criteria are independent in the developed approach; further study can consider integrating the Choquet integral into the proposed method to take the dependency between criteria into account. Meanwhile, with the rapid development of human social-economic activities, some new and important main-criteria and sub-criteria should be discussed and added in the developed approach because the evaluation main-criteria and sub-criteria used in this paper were adopted in [2]. Last but not least, further research should consider developing a decision support system based on the proposed approach to facilitate the managers of the firms to make decisions quickly and rationally.

Acknowledgments: The authors are very grateful to the anonymous reviewers and the editor for their insightful and constructive comments and suggestions that have led to an improved version of this paper. The work was supported by the National Natural Science Foundation of China (No. 71661010), the Major Program of the National Social Science Foundation of China (No. 15ZDC021), the Natural Science Foundation of Jiangxi Province of China (No. 20161BAB211020) and the Technology Project of Education Department of Jiangxi Province of China (No. GJJ160455). 
Author Contributions: Xiaolu Zhang contributed to the study design and wrote the manuscript. Xiaoming Xing helped edit and revise the manuscript. All authors participated in reading and finalizing the manuscript.

Conflicts of Interest: The authors declare no conflict of interest.

\section{References}

1. Chan, H.K.; Wang, X.; White, G.R.T.; Yip, N. An extended fuzzy-AHP approach for the evaluation of green product designs. IEEE Trans. Eng. Manag. 2013, 60, 327-339. [CrossRef]

2. Wang, X.; Chan, H.K. A hierarchical fuzzy TOPSIS approach to assess improvement areas when implementing green supply chain initiatives. Int. J. Prod. Res. 2013, 51, 3117-3130. [CrossRef]

3. Opricovic, S. Multicriteria Optimization of Civil Engineering Systems. Ph.D. Thesis, Faculty of Civil Engineering, University of Belgrade, Belgrade, Serbia, 1998; pp. 5-21.

4. Pang, Q.; Wang, H.; Xu, Z.S. Probabilistic linguistic term sets in multi-attribute group decision making. Inform. Sci. 2016, 369, 128-143. [CrossRef]

5. Entezaminia, A.; Heydari, M.; Rahmani, D.A. multi-objective model for multi-product multi-site aggregate production planning in a green supply chain: Considering collection and recycling centers. J. Manuf. Syst. 2016, 40, 63-75. [CrossRef]

6. Kannan, D.; Khodaverdi, R.; Olfat, L.; Ahmad, J.; Ali, D. Integrated fuzzy multi criteria decision making method and multi-objective programming approach for supplier selection and order allocation in a green supply chain. J. Clean. Prod. 2013, 47, 355-367. [CrossRef]

7. Kusi-Sarpong, S.; Sarkis, J.; Wang, X. Assessing green supply chain practices in the Ghanaian mining industry: A framework and evaluation. Int. J. Prod. Econ. 2016, 181, 325-341. [CrossRef]

8. Tramarico, C.L.; Salomon, V.A.P.; Marins, F.A.S. Multi-criteria assessment of the benefits of a supply chain management training considering green issues. J. Clean. Prod. 2017, 142, 249-256. [CrossRef]

9. Wang, Z.; Mathiyazhagan, K.; Xu, L.; Diabat, A. A decision making trial and evaluation laboratory approach to analyze the barriers to Green Supply Chain Management adoption in a food packaging company. J. Clean. Prod. 2016, 117, 19-28. [CrossRef]

10. Sarkis, J. How Green Is the Supply Chain? Practice and Research; Graduate School of Management, Clark University: Worcester, MA, USA, 1999.

11. Srivastava, S.K. Green supply-chain management: A state-of-the-art literature review. Int. J. Manag. Rev. 2007, 9, 53-80. [CrossRef]

12. Sarmiento, R.; Thomas, A. Identifying improvement areas when implementing green initiatives using a multitier AHP approach. Benchmark. Int. J. 2010, 17, 452-463. [CrossRef]

13. Rao, P.; Holt, D. Do green supply chains lead to competitiveness and economic performance? Int. J. Oper. Prod. Manag. 2005, 25, 898-916. [CrossRef]

14. Vachon, S. Green supply chain practices and the selection of environmental technologies. Int. J. Prod. Res. 2007, 45, 4357-4379. [CrossRef]

15. Zhu, Q.; Sarkis, J.; Lai, K. Green supply chain management implications for “closing the loop". Transp. Res. E Logist. Transp. Rev. 2008, 44, 1-18. [CrossRef]

16. Govindan, K.; Kadziński, M.; Sivakumar, R. Application of a novel PROMETHEE-based method for construction of a group compromise ranking to prioritization of green suppliers in food supply chain. Omega 2017, 71, 129-145. [CrossRef]

17. Azadi, M.; Shabani, A.; Khodakarami, M.; Reza, F.S. Planning in feasible region by two-stage target-setting DEA methods: An application in green supply chain management of public transportation service providers. Transp. Res. E Logist. Transp. Rev. 2014, 70, 324-338. [CrossRef]

18. Mathiyazhagan, K.; Diabat, A.; Al-Refaie, A. Application of analytical hierarchy process to evaluate pressures to implement green supply chain management. J. Clean. Prod. 2015, 107, 229-236. [CrossRef]

19. Sari, K. A novel multi-criteria decision framework for evaluating green supply chain management practices. Comput. Ind. Eng. 2017, 105, 338-347. [CrossRef]

20. Tseng, M.L.; Lin, Y.H.; Tan, K.; Chen, R.H.; Chen, Y.H. Using TODIM to evaluate green supply chain practices under uncertainty. Appl. Math. Model. 2014, 38, 2983-2995. [CrossRef]

21. Uygun, Ö.; Dede, A. Performance evaluation of green supply chain management using integrated fuzzy multi-criteria decision making techniques. Comput. Ind. Eng. 2016, 102, 502-511. [CrossRef] 
22. Yu, M.C.; Su, M.H. Using Fuzzy DEA for Green Suppliers Selection Considering Carbon Footprints. Sustainability 2017, 9, 495. [CrossRef]

23. Govindan, K.; Khodaverdi, R.; Vafadarnikjoo, A. Intuitionistic fuzzy based DEMATEL method for developing green practices and performances in a green supply chain. Expert. Syst. Appl. 2015, 42, 7207-7220. [CrossRef]

24. Kusi-Sarpong, S.; Bai, C.; Sarkis, J.; Wang, X.P. Green supply chain practices evaluation in the mining industry using a joint rough sets and fuzzy TOPSIS methodology. Resour. Pol. 2015, 46, 86-100. [CrossRef]

25. Rostamzadeh, R.; Govindan, K.; Esmaeili, A.; Sabaghi, S. Application of fuzzy VIKOR for evaluation of green supply chain management practices. Ecol. Indic. 2015, 49, 188-203. [CrossRef]

26. Shen, L.; Olfat, L.; Govindan, K.; Khodaverdi, R.; Diabat, A. A fuzzy multi criteria approach for evaluating green supplier's performance in green supply chain with linguistic preferences. Resour. Conserv. Recycl. 2013, 74, 170-179. [CrossRef]

27. Tseng, M.L.; Lim, M.; Wu, K.J.; Zhou, L.; Dat Bui, D.T. A novel approach for enhancing green supply chain management using converged interval-valued triangular fuzzy numbers-grey relation analysis. Resour. Conserv. Recycl. 2017. [CrossRef]

28. Zhang, X.; Xu, Z.; Liu, M. Hesitant trapezoidal fuzzy QUALIFLEX method and its application in the evaluation of green supply chain initiatives. Sustainability 2016, 8, 952. [CrossRef]

29. Büyüközkan, G.; Çifçi, G. A novel hybrid MCDM approach based on fuzzy DEMATEL, fuzzy ANP and fuzzy TOPSIS to evaluate green suppliers. Expert Syst. Appl. 2012, 39, 3000-3011. [CrossRef]

30. Chithambaranathan, P.; Subramanian, N.; Gunasekaran, A.; Palaniappan, K. Service supply chain environmental performance evaluation using grey based hybrid MCDM approach. Int. J. Prod. Econ. 2015, 166, 163-176. [CrossRef]

31. Liao, C.N.; Fu, Y.K.; Wu, L.C. Integrated FAHP, ARAS-F and MSGP methods for green supplier evaluation and selection. Technol. Econ. Dev. Econ. 2016, 22, 651-669. [CrossRef]

32. Malviya, R.K.; Kant, R. Hybrid decision making approach to predict and measure the success possibility of green supply chain management implementation. J. Clean. Prod. 2016, 135, 387-409. [CrossRef]

33. Yazdani, M.; Chatterjee, P.; Zavadskas, E.K.; Zolfani, S.H. Integrated QFD-MCDM framework for green supplier selection. J. Clean. Prod. 2017, 142, 3728-3740. [CrossRef]

34. Zolfani, S.H.; Chen, I.S.; Rezaeiniya, N.; Tamošaitienè, J. A hybrid MCDM model encompassing AHP and COPRAS-G methods for selecting company supplier in Iran. Technol. Econ. Dev. Econ. 2012, 18, 529-543. [CrossRef]

35. Mardani, A.; Jusoh, A.; Zavadskas, E.K.; Cavallaro, F.; Khalifah, Z. Sustainable and renewable energy: An overview of the application of multiple criteria decision making techniques and approaches. Sustainability 2015, 7, 13947-13984. [CrossRef]

36. Mardani, A.; Zavadskas, E.K.; Khalifah, Z.; Zakuan, N.; Jusoh, A.; Nor, K.M.; Khoshnoudi, M. A review of multi-criteria decision-making applications to solve energy management problems: Two decades from 1995 to 2015. Renew. Sustain. Energy Rev. 2017, 71, 216-256. [CrossRef]

37. San Cristóbal, J.R. Multi-criteria decision-making in the selection of a renewable energy project in spain: The Vikor method. Renew. Energy 2011, 36, 498-502. [CrossRef]

38. Opricovic, S.; Tzeng, G.H. Multicriteria planning of post-earthquake sustainable reconstruction. Comput. Aided Civ. Infrastruct. Eng. 2002, 17, 211-220. [CrossRef]

39. Yalcin, N.; Bayrakdaroglu, A.; Kahraman, C. Application of fuzzy multi-criteria decision making methods for financial performance evaluation of Turkish manufacturing industries. Expert Syst. Appl. 2012, 39, 350-364. [CrossRef]

40. Tzeng, G.H.; Lin, C.W.; Opricovic, S. Multi-criteria analysis of alternative-fuel buses for public transportation. Energy Pol. 2005, 33, 1373-1383. [CrossRef]

41. Zhang, X. Multicriteria Pythagorean fuzzy decision analysis: A hierarchical QUALIFLEX approach with the closeness index-based ranking methods. Inf. Sci. 2016, 330, 104-124. [CrossRef]

42. Li, K.W.; Wang, Z.J.; Tong, X. Acceptability analysis and priority weight elicitation for interval multiplicative comparison matrices. Eur. J. Oper. Res. 2016, 250, 628-638. [CrossRef]

43. Wang, Z.J.; Li, K.W. A multi-step goal programming approach for group decision making with incomplete interval additive reciprocal comparison matrices. Eur. J. Oper. Res. 2015, 242, 890-900. [CrossRef]

44. Zhang, X.; Xu, Z. Interval programming method for hesitant fuzzy multi-attribute group decision making with incomplete preference over alternatives. Comput. Ind. Eng. 2014, 75, 217-229. [CrossRef] 
45. Zhang, X.; Xu, Z.; Wang, H. Heterogeneous multiple criteria group decision making with incomplete weight information: A deviation modeling approach. Inf. Fusion 2015, 25, 49-62. [CrossRef]

46. Zhang, Y.; Li, K.W.; Wang, Z.J. Prioritization and aggregation of intuitionistic preference relations: A multiplicative-transitivity-based transformation from intuitionistic judgment data to priority weights. Group Decis. Negot. 2017, 26, 409-436. [CrossRef]

47. Sayadi, M.K.; Heydari, M.; Shahanaghi, K. Extension of VIKOR method for decision making problem with interval numbers. Appl. Math. Model. 2009, 33, 2257-2262. [CrossRef]

48. Kaya, T.; Kahraman, C. Multicriteria renewable energy planning using an integrated fuzzy VIKOR \& AHP methodology: The case of Istanbul. Energy 2010, 35, 2517-2527.

49. Chen, L.Y.; Wang, T.C. Optimizing partners' choice in IS/IT outsourcing projects: The strategic decision of fuzzy VIKOR. Int. J. Prod. Econ. 2009, 120, 233-242. [CrossRef]

50. Opricovic, S. Fuzzy VIKOR with an application to water resources planning. Expert Syst. Appl. 2011, 38, 12983-12990. [CrossRef]

51. Shemshadi, A.; Shirazi, H.; Toreihi, M.; Tarokh, M.J. A fuzzy VIKOR method for supplier selection based on entropy measure for objective weighting. Expert Syst. Appl. 2011, 38, 12160-12167. [CrossRef]

52. Devi, K. Extension of VIKOR method in intuitionistic fuzzy environment for robot selection. Expert Syst. Appl. 2011, 38, 14163-14168. [CrossRef]

53. Park, J.H.; Cho, H.J.; Kwun, Y.C. Extension of the VIKOR method for group decision making with interval-valued intuitionistic fuzzy information. Fuzzy Optim. Decis. Mak. 2011, 10, 233-253. [CrossRef]

54. Liao, H.; Xu, Z.A. VIKOR-based method for hesitant fuzzy multi-criteria decision making. Fuzzy Optim. Decis. Mak. 2013, 12, 373-392. [CrossRef]

55. Zhang, N.; Wei, G. Extension of VIKOR method for decision making problem based on hesitant fuzzy set. Appl. Math. Model. 2013, 37, 4938-4947. [CrossRef]

56. Liao, H.; Xu, Z.; Zeng, X.J. Hesitant fuzzy linguistic VIKOR method and its application in qualitative multiple criteria decision making. IEEE Trans. Fuzzy Syst. 2015, 23, 1343-1355. [CrossRef]

57. Mardani, A.; Zavadskas, E.K.; Govindan, K.; Aslan, A.M.; Ahmad, J. VIKOR technique: a systematic review of the state of the art literature on methodologies and applications. Sustainability 2016, 8, 37. [CrossRef]

58. Zhang, X. Non-homogeneous linguistic multi-criteria group decision making with aspiration. Tech. Rep. 2017, 1-15.

59. Yager, R. An approach to ordinal decision making. Int. J. Approx. Reason. 1995, 12, 237-261. [CrossRef]

60. Rodriguez, R.M.; Martinez, L.; Herrera, F. Hesitant fuzzy linguistic term sets for decision making. IEEE Trans. Fuzzy Syst. 2012, 20, 109-119. [CrossRef]

61. Wu, Z.; Xu, J. Possibility distribution-based approach for MAGDM with hesitant fuzzy linguistic information. IEEE Trans. Cybern. 2016, 46, 694-705. [CrossRef] [PubMed]

62. Gu, X.J.; Xu, Z.S. Novel Basic Operational Laws for Linguistic Terms, Hesitant Fuzzy Linguistic Term Sets and Probabilistic Linguistic Term Sets. Inform. Sci. 2016, 372, 407-427. [CrossRef]

63. Lin, M.; Xu, Z.; Zhai, Y. Multi-attribute group decision-making under probabilistic uncertain linguistic environment. J. Oper. Res. Soc. 2017. [CrossRef]

64. Zhang, Y.; Xu, Z.; Wang, H.; Liao, H. Consistency-based risk assessment with probabilistic linguistic preference relation. Appl. Soft. Comput. 2016, 49, 817-833. [CrossRef]

65. Zhai, Y.; Xu, Z.; Liao, H. Probabilistic linguistic vector-term set and its application in group decision making with multi-granular linguistic information. Appl. Soft. Comput. 2016, 49, 801-816. [CrossRef]

(C) 2017 by the authors. Licensee MDPI, Basel, Switzerland. This article is an open access article distributed under the terms and conditions of the Creative Commons Attribution (CC BY) license (http://creativecommons.org/licenses/by/4.0/). 